\title{
LA SOLTERÍA VIRTUOSA: DIGNIDAD, UTILIDAD Y EL DISCURSO SOBRE EL CELIBATO FEMENINO EN LA ESPAÑA CONTEMPORÁNEA (1820-1950)
}

\author{
VIRTUOUS SINGLEDOM: DIGNITY, USEFULNESS \\ AND THE DISCOURSE ON FEMALE CELIBACY \\ IN MODERN SPAIN (1820-1950)
}

\author{
Alejandro Camino*, Darina Martykánová
} Universidad Autónoma de Madrid, Madrid, España

\begin{abstract}
RESUMEN: La soltería femenina fue a menudo objeto de sorna y de ridículo en la cultura popular y en el debate intelectual en la España contemporánea, algo que se ha interpretado como un signo de rechazo en favor del matrimonio y/o de miedo a su potencial subversivo. Sin embargo, mostraremos que era un estado que gozaba de alto grado de aceptación y respetabilidad en la sociedad española de la época siempre y cuando se cumpliesen una serie de requisitos. Si bien la historiografía ha ido construyendo la noción de que fundamentalmente existieron dos estados dignos para una mujer en las construcciones de género dominantes en la cultura política católica, la soltería religiosa y el matrimonio, existió una tercera vía defendida públicamente: la soltería laica. Para analizar estas cuestiones, hemos optado por una exploración a largo plazo de la inestable jerarquía de prestigio que existía entre los distintos modelos de feminidad.
\end{abstract}

PALABRAS CLAVE: soltería, catolicismo, mujeres, modelos de feminidad, España.

ABSTRACT: Single women were often ridiculed in the popular culture and in the intellectual discourse in nineteenth- and twentieth-century Spain. Existing works on this subject have tended to interpret this as a sign of rejection and/or of fear concerning the subversive potential of a woman remaining single. Basing ourselves on recent research on gender in Catholic thought, we nonetheless argue that celibacy - provided it followed certain rules - was not only accepted, but held in great regard in Spanish society of that period. While the historiography has construed the notion that there were, basically, two dignified states for a woman in the Catholic political culture: the religious celibacy and marriage, we argue that a third way existed and was explicitly defended: «secular» celibacy. To analyse this issue, we explore the shifting hierarchy of prestige of the different models of femininity in the long run.

KEYWORDS: celibacy, Catholicism, women, femininity models, Spain.

* Correspondencia a: Alejandro Camino. Universidad Autónoma de Madrid, Ciudad Universitaria de Cantoblanco, Facultad de Filosofía y Letras, Departamento de Historia Contemporánea. C/ Francisco Tomás y Valiente, 1, 28049, Madrid (Spain) - alejandro.camino@uam.es - https://orcid.org/0000-0003-1532-8239

Cómo citar: Camino, Alejandro; Martykánová, Darina (2021). «La soltería virtuosa: dignidad, utilidad y el discurso sobre el celibato femenino en la España contemporánea (1820-1950)m; Historia Contemporánea, 66, 337-369. (https://doi.org/10.1387/hc.21210).

Recibido: 31 octubre, 2019; aceptado: 28 febrero, 2020.

ISSN 1130-2402 — elSSN 2340-0277 / (C) 2020 UPV/EHU

cc) $\rightleftharpoons$ Esta obra está bajo una Licencia

cc) Creative Commons Atribución-NoComercial-SinDerivadas 4.0 Internacional 
Alejandro Camino, Darina Martykánová

\section{Introducción}

Si hay enfermedades que afectan con preferencia á las personas celibatas, el arte [de curar] tiene un remedio más para combatirlas. Se puede esperar del matrimonio la curación de la mayor parte de las enfermedades que tienen su origen en el celibatismo, y su remedio profiláctico en el uso de los placeres del amor. ${ }^{1}$

La solterona fea y buena tiene dentro de la familia noble y cristiana misión que cumplir: cuidar y acompañar a sus padres ancianos o enfermos. ¡Cuántos extravíos sentimentales del viudo solitario serían evitados por la abnegación y el cariño de una hija indiferente a los pérfidos llamamientos del amor codicioso! ${ }^{2}$

Salvo valiosas excepciones, la bibliografía que hace referencia a la soltería en España suele interpretar la sorna y la ridiculización desplegadas hacia las solteras, en la literatura decimonónica y de la primera mitad del siglo XX, como signo del rechazo a la soltería femenina o del miedo al potencial subversivo de ésta. Se pone énfasis en el estereotipo de «la solterona» que representaba a la soltera como fea, amargada y resentida. Sin embargo, tanto las estadísticas como el análisis matizado de las actitudes que las personas de la época mostraban hacia las solteras, indican que la soltería era un estado no solamente muy extendido, sino bien aceptado en la sociedad española de la época. De hecho, era una opción vital que se consideraba respetable y digna para una mujer ${ }^{3}$. Proponemos entender esta tensión introduciendo la categoría analítica de jerarquía de prestigio de los modelos de feminidad. Postulamos que, si bien es cierto que el matrimonio y la maternidad se llegaron a presentar como elementos fundamentales de la feminidad modélica en la segunda mitad del XIX y el primer tercio del XX, la soltería virtuosa era una manera de entender y vivir la feminidad no solo aceptable, sino respetable. Al mismo tiempo reconocemos que se vio subordinada al modelo de la mujer como madre de familia mediante el discurso (ridiculización) y prácticas (castigo legal y oprobio social para las mujeres por el sexo

${ }^{1}$ Dr. Jean-Baptiste Bousquet, comentado de forma crítica por un médico español: Décadas médico-quirúrgicas, Tomo I, N.V (1820 o 1821), p. 211.

${ }^{2}$ Ramón y Cajal, 1944 [1905], p. 79.

${ }^{3}$ La dignidad con la que contaba esta tercera vía no fue sólo propia de España, sino también de los países mayoritariamente católicos: Gruziel, 2012, p. 150. Sobre el concepto de dignidad: Aresti, 2015. 
extraconyugal). Sin embargo, siendo dicha jerarquía de prestigio una construcción discursiva inestable, quienes defendieron la dignidad de una soltería virtuosa pudieron llegar hasta a subvertir esta jerarquía y situar la soltería virtuosa por encima de algunas formas de matrimonio.

La historiografía ha ido construyendo la noción de que básicamente existían dos estados dignos para una mujer en las construcciones de género dominantes en la cultura política católica: por un lado, la soltería religiosa, quedando la monja casada con Dios, y, por otro lado, el matrimonio terrenal y la maternidad biológica. En consecuencia, las mujeres debían elegir entre casarse con un hombre o hacerlo con Dios y de su situación emanaba la maternidad biológica o la social. Con las tendencias secularizantes surgidas de la Ilustración (e incluso antes, desde que la Reforma protestante planteara una crítica al celibato eclesiástico y a la contemplación ociosa), el celibato se vio seriamente cuestionado, tanto por la crítica anticlerical de la inutilidad de la vida contemplativa, como por el impacto del discurso pronatalista naturalizado mediante argumentos médicos ${ }^{4}$. El panorama fue, sin embargo, más complejo. Existía también una tercera vía, la soltería laica. Muchas mujeres se quedaron solteras sin hacer votos, ya fuese por elección o por no tener otras opciones. Es esta opción vital, particularmente en su versión célibe, la que constituye el núcleo de nuestro análisis.

\section{Antecedentes históricos del debate sobre la soltería}

Desde la Edad Media, en los reinos que actualmente conforman España, las leyes y costumbres dotaban a las mujeres solteras de una cierta capacidad de actuación y de aceptación social ${ }^{5}$. Asimismo, las tasas de soltería laica eran altas, igual que en otros países europeos (superando el $20 \%)^{6}$. A muchas mujeres les impusieron la soltería desde las familias, implícita o explícitamente. No era atípico que una de las hijas quedara prácticamente destinada a cuidar de sus familiares. En familias de pocos recursos, algunas hijas acabaron colocándose en el servicio doméstico de forma temporal, hasta que contrajeran el matrimonio, mientras que para otras era un destino permanente. La Iglesia católica también consi-

\footnotetext{
${ }^{4}$ Véase: Beauvalet-Boutouyrie, 2001, pp. 127-141; Weisner-Hanks, 2000; Apetrei, 2016 pp. 41-60.

5 Pérez, 2010; Sánchez, 2008.

6 Beauvalet-Boutouyrie, 2001, p. 131.
} 
deró digna la soltería laica siempre y cuando fuera virtuosa (lo que, básicamente, quería decir célibe), ya que estaba destinada a cumplir un papel importante en la familia y en la comunidad, aunque el estado más perfecto y valioso para la Iglesia y sus voces intelectuales era la soltería religiosa, puesto que estaba por encima del sacramento católico del matrimonio. Además de estas opciones de soltería virtuosa que implicaban renunciar a todas las formas de vida sexual que pudieran llevar al embarazo o causar escándalo público, la sociedad española estigmatizaba, pero no excluía, otras formas de ser soltera: la prostituta y la querida, este último tolerado siempre y cuando el hombre fuera de una clase social más alta que la mujer ${ }^{7}$.

La alabanza tradicional del celibato femenino en el discurso de la Iglesia católica coexistió durante la Época Moderna con una fuerte presión social a favor del matrimonio como herramienta de cohesión social, así como con ciertas prácticas y dinámicas estructurales que hacían la soltería menos apetecible para las mujeres. Además, esta glorificación de la soltería célibe se vio cuestionada desde los tiempos de la Ilustración por el discurso pronatalista que postulaba la maternidad prácticamente como un deber, usando argumentos médicos, biológico-naturales, económicos y de bien común. Estas críticas (pro-natalismo, el discurso médico que conectaba la salud y la práctica sexual, los discursos protestantes y anticlericales sobre la perversión del celibato) se fueron refinando y agudizando en el siglo XIX ${ }^{8}$. Sin embargo, mantenemos que, en España, como en algunos otros países como el Reino Unido, Portugal, Italia o Austria, la soltería seguía siendo no solo aceptada, sino respetada y digna ${ }^{9}$. Esto se debía no solamente a las dinámicas sociales que favorecían altas tasas de soltería femenina ${ }^{10}$, sino también al discurso legitimador de la misma desplegado por los médicos, reformadores sociales y eclesiásticos y también por las mujeres cultas, muchas de ellas solteras, que formaban parte de la opinión pública.

A pesar de los retos discursivos a los que tuvo que hacer frente el discurso eclesiástico que legitimaba y ensalzaba la soltería femenina religiosa a nivel transnacional, este siguió reproduciéndose y renovándose a lo largo de

7 Para la variedad y cambios históricos en las actitudes oficiales y sociales hacia la prostitución en España: Vázquez, 1998.

8 Yeo, 1999.

9 En las primeras dos décadas del siglo Xx, en los países checos bajo el Imperio austríaco las maestras tenían que ser solteras por ley: Šlehofer, 2016.

10 Muñoz, 2001. 
los siglos XVIII, XIX y XX ${ }^{11}$. Al discurso tradicional de la Iglesia católica sobre el celibato como una opción para los fuertes, se sumó en la narrativa nacional del siglo XIX la admiración sentida por las monjas como escritoras y consejeras de hombres poderosos en la monarquía hispana, integrando en el panteón nacional a figuras como Santa Teresa de Jesús, sor Inés de la Cruz o, con una ambigüedad reveladora del recelo que sentían muchos hombres decimonónicos hacia la intervención de las mujeres en la política, María de Jesús de Ágreda, amiga y consejera de Felipe IV. La imagen positiva de la monja tenía también su forma menos intimidante, más acorde con la domesticidad decimonónica: la tía monjita, un clásico de las «familias bien».

Esta variedad de las formas «respetables» $\mathrm{y}$ «virtuosas» de la soltería femenina, fue aprovechada por las mujeres tanto para resistir la presión hacia el matrimonio, como para dignificar su soltería, independientemente de que ésta fuese por decisión propia o producto de circunstancias. Incluso se utilizó para subvertir la jerarquía de prestigio entre los modelos de feminidad a favor de la soltería. Muchas mujeres exploraron las posibilidades discursivas que les ofrecía la defensa católica del celibato y combinaron elementos de este discurso con los valores hegemónicos del liberalismo de la época, como autonomía y libertad para reivindicar la dignidad de la soltería. El concepto de utilidad social, en tanto que pilar de la vida digna, les permitió movilizar imaginarios/lenguajes políticos reconocibles no sólo desde el catolicismo y liberalismo, sino también por el socialismo. De este modo, la soltería virtuosa es una categoría que engloba a las solteras laicas y religiosas que cumplieron su misión maternal no en el sentido biológico, sino aplicando las supuestas virtudes naturales (otorgadas por Dios) que la cultura católica les asignaba dedicándose a la atención de familiares y de la sociedad, con obras de apostolado y acciones caritativas, patrióticas y sociales ${ }^{12}$.

\section{Celibato, salud y utilidad pública: la pugna decimonónica}

Si bien es cierto que la continuidad del discurso católico sobre el celibato como una manera digna de vivir la vida terrenal se observa a

11 Sobre la importancia a nivel transnacional de los debates sobre la mujer y la familia en la definición de una identidad europea más secularizada en los siglos XVIII y XIX, véase, por ejemplo, Miller, 2017; Malečková, 2002.

12 Algo similar fue defendido por Morales y Vieitez, 2017, pp. 183-184. 
lo largo del siglo XIX, el discurso ilustrado que insistía en la utilidad social de la actividad humana y en el fomento de la población, y quizás también cierto anticlericalismo popular, empujaron a refinar los argumentos a favor de la soltería virtuosa. Aparecieron nuevas formas de justificarla y dignificarla en los campos en los que se empezó a debatir este tema, por ejemplo, la medicina o la reforma política. En los siguientes apartados exploraremos los discursos sobre la soltería desplegados en el siglo XIX desde las distintas plataformas, mostrando sus diferencias y similitudes, pero también la pluralidad interna y contradicciones en cada campo.

El discurso médico se suele presentar como una de las fuerzas motrices a la hora de articular y promover la noción de la diferencia sexual, el maternalismo y el biologismo en la redefinición de las relaciones de género en los siglos XVIII y XIX ${ }^{13}$. En cambio, la cuestión de celibato deja en evidencia la multiplicidad de las posturas que caracterizaron el discurso médico transnacional en los dos primeros tercios del siglo XIX. Muchos médicos, en distintos países del mundo, promovieron la idea de que la abstinencia sexual pudiera ser causa de numerosas enfermedades o contribuir a su desarrollo, igual que los excesos sexuales exponían a otras. Sin embargo, muchos médicos españoles, incluso los que juzgaban estas teorías como válidas, no estaban dispuestos a aceptar esta argumentación de forma acrítica y a menudo las matizaciones eran a favor de la soltería virtuosa. Al resumir en Décadas médicos-quirúrgicas (1821) un médico español, quizás el editor de la revista Manuel Hurtado de Mendoza (1783-1849), próximo a las posturas del liberalismo avanzado, las tesis de la obra Del matrimonio considerado como medio preservativo y curativo de las enfermedades ${ }^{14}$, escrito por el médico francés Jean-Baptiste Bousquet (1794-1872) ${ }^{15}$, el español expresó su acuerdo con algunos de los postulados de Bousquet y de otros como el famoso médico e higienista alemán Christoph-Wilhelm Hufeland (1762-1836) sobre los poderes terapéuticos de los «placeres del amor» a la hora de prevenir o curar la escrófula y otras enfermedades. De este modo, admitió que las solteras y los solteros célibes podían estar más expuestas al desarrollo de la tuberculosis y algunos cánceres:

\footnotetext{
13 Laqueur, 2003.

14 Bousquet, 1820.

15 Frond, 1865.
} 
El matrimonio precave en uno y otro sexo las enfermedades espasmódicas y nerviosas variadas que resultan de una continencia observada con demasiado rigor. Lo mismo sucede con algunas enfermedades puramente orgánicas del aparato genital en el hombre y del uterino en la mujer, como son los cuerpos fibrosos, el cáncer de la matriz, el de los pechos, etc. que se observan más frecuentemente en las personas del sexo femenino que han guardado una continencia perfecta que en las que han cumplido con las funciones de madre á que la naturaleza las había destinado en la sociedad. El matrimonio regulariza el flujo menstruo y precave ó disipa los accidentes nerviosos que resultan de la amenorrea o dismenorrea. ${ }^{16}$

Suscribía además el anónimo médico español la tesis de que el celibato podría contribuir al desarrollo de los trastornos mentales, ya que «nadie ignora cuantas veces una enajenación mental es efecto de un amor contrariado, de la descomposición de un casamiento que estaba próximo a verificarse, de un estado de viudez precoz y religiosamente observado, y en una palabra, de la continencia absoluta.» Sin embargo, no se mostraba dispuesto a aceptar todo lo postulado por el médico francés sobre los daños del celibato y los beneficios de los «placeres del amor». La escasa longevidad de los célibes postulada por el francés fue uno de los puntos en los que el español mostró reticencias a la hora de asumir la hipótesis del celibato como dañino para la salud y dar por demostrados los efectos positivos de la copulación en el marco legítimo del matrimonio. Después de resumir con aprobación el escepticismo de Bousquet en cuanto a la capacidad curativa de los «placeres del amor» en casos del cáncer de mama y en las lesiones orgánicas del ovario y del útero, y su convencimiento de que «estos goces» hasta aceleran «el momento funesto en la tisis declarada», el comentarista español añadió una crítica contundente de la insistencia de Bousquet en los efectos provechosos de los aspectos más sensuales del coito matrimonial:

Nadie creerá que, después de unos principios tan sabios, escribe el autor [Bousquet] las frases siguientes: «Examinando la proposición contraria, la hallaremos igualmente verdadera; es decir, que si el matrimonio no cura todas las enfermedades de que puede mirarse como profiláctico, facilita algunas veces la curación de algunas de que no es preservativo admirable; por ejemplo ¿se podrá dudar que la emoción que

16 Décadas médico-quirúrgicas, Tomo I, N.V (1820-21), p. 210. 
Alejandro Camino, Darina Martykánová

precede al acto de la propagación, la alteración del sistema nervioso en el momento mismo en que se verifica aquel, y el descanso voluptuoso que le sucede no presentan tantas circunstancias propias para avivar el principio conservador y sacarle de la seguridad funesta en que se ha sumergido, al paso que sin su noticia, destruyen sordamente los instrumentos de la vida las flemasias crónicas y las desorganizaciones lentas.» Esta aserción parece muy hipotética [sentencia el médico español].

[...] Por lo demás, sea lo que quiera acerca de la predilección que manifiesta el doctor Bousquet por el matrimonio, es preciso convenir que la unión de los sexos no puede aconsejarse indistintamente a todo el mundo [concluye el comentarista español] y que hay personas (por fortuna en pequeño número) a quienes la naturaleza parece que ha condenado al celibato. «Son aquellas cuyos órganos reproductores están afectados de ciertos vicios de conformación que no pueden curar todos los remedios del arte; las que padecen enfermedades transmisibles por la generación y que no pueden dejar a sus hijos más que la triste herencia de una vida envenenada por el dolor, etc., etc...». ${ }^{17}$

Puede que la precaución del comentarista español se debiera al rigor científico y es cierto que hasta hablaba del celibato en términos de condena. Sin embargo, no estaba dispuesto a aceptar acríticamente las afirmaciones sobre la menor esperanza de vida de los célibes ni sobre los poderes preventivos y curativos de los placeres sensuales en general. Subrayó en varias ocasiones que el matrimonio no podía aconsejarse a todo el mundo, entre otras cosas, por razones de higiene.

Mientras que el médico anónimo de 1821 parecía aceptar en términos generales los efectos saludables de la vida sexual dentro del matrimonio, y su defensa de la soltería era relativamente tibia, Pedro Felipe Monlau (1808-1870) a mediados del siglo XIX fue mucho más lejos en su legitimación del celibato. Como ha mostrado Marie Walin, el médico español de proyección internacional planteó que el celibato podía tener efectos claramente positivos para la salud. En cierto modo se trata de un caso que refleja como espejo el de las Décadas médico-quirúrgicas del Trienio que acabamos de analizar. Walin pone en evidencia cómo el médico francés que comentó la traducción de la obra del célebre médico español manifestó su admiración por la obra de Monlau, y, sin embargo, rechazó como influida por un catolicismo exacerbado típico de los españoles la defensa que hacía Monlau del celibato. Monlau afirmaba que la abstinencia sexual

17 Ibid., pp. 212-213. 
podía ser hasta recomendable, no sólo para los eclesiásticos, sino también para hombres que necesitasen gastar mucha energía en su profesión, como los científicos o los altos mandos militares. Eso chocaba frontalmente con los postulados hegemónicos en Francia sobre los efectos benéficos de la eyaculación y del coito ${ }^{18}$.

\section{Las solteras de dudosa virtud: los límites de la intervención social}

A lo largo del siglo XIX la soltería fue cuestionada en tanto que estado deseable. Tanto los médicos influyentes en la comunidad científica transnacional, como los anticlericales en los países católicos, alegaron que el celibato perjudicaba la salud de los hombres y de las mujeres ${ }^{19}$. Al mismo tiempo persistía la noción de que la práctica sexual fuera del matrimonio era indeseable, sobre todo para las mujeres. Sin embargo, al ensalzarse la práctica sexual en sí como natural y saludable, se pueden observar, tanto en España como en Francia y Centroeuropa, actitudes de tolerancia y comprensión hacia las mujeres solteras transgresoras. Dejando de lado los grupos como los fourieristas que defendieron abiertamente el amor libre como una manera virtuosa de vivir $^{20}$, proliferaron posturas menos rupturistas que no ensalzaron la práctica sexual de las solteras, sino que mostraron comprensión hacia lo que seguían entendiendo como transgresión y propusieron soluciones centradas en el cambio del comportamiento masculino y en el énfasis de la responsabilidad de toda la sociedad, que debía plasmarse en reformas institucionales en vez de en la persecución de las transgresoras.

Se desarrolló un discurso surgido de la Ilustración que abogaba por una actitud más comprensiva hacia la maternidad fuera del matrimonio y, sobre todo, por la eliminación de todas las medidas discriminatorias hacia los hijos «bastardos». Más adelante, la prostitución, una práctica tradicionalmente estigmatizada, pero al mismo tiempo social y legalmente sancionada desde hacía siglos, fue reconceptualizada por el discurso abolicionista como un problema social que victimizaba a las mujeres de las clases

18 Walin, 2021.

${ }^{19}$ El influyente tratado médico de Jean-Baptiste Louyer Villermay, 1832, p. 118, mantiene que «la privación de los placeres del amor» es una de las causas principales de la histeria, siendo «la continencia» la causa de la histeria en «nueve de diez mujeres o chicas histéricas».

${ }^{20}$ Pro, 2015, p. 33. 
desfavorecidas, a menudo víctimas de la depredación e irresponsabilidad masculina. Ensalzando la maternidad y presentándola además como el estado natural para las mujeres, tanto los ilustrados, como los médicos liberales o los promotores de la reforma social no es que aprobaran el sexo fuera del matrimonio, pero lo plantearon como fruto de una pulsión natural y, en principio, saludable. Un hijo así concebido no debía sufrir las consecuencias del comportamiento de sus progenitores; los reformistas ilustrados y los revolucionarios liberales solían abogar por la eliminación del estigma legal de los «bastardos» ${ }^{21}$. En ocasiones, las madres solteras hasta dejaron de verse como pecadoras reprobables, sino que se les presentaba como seres débiles por naturaleza víctimas de la depredación masculina, y, como tales, merecían un trato benévolo y un apoyo social.

Podemos observar este discurso en el caso de un médico durante el Trienio constitucional, que se preocupaba por la dureza del sistema judicial hacia las madres solteras. Es más, ponía el foco en el papel de los médicos en la persecución de éstas en casos en los que había que decidir si la mujer solo ocultó el parto o si cometió infanticidio ${ }^{22}$. El autor mostró una gran compasión hacia las madres solteras a la vez que se insertó en calidad de experto en un debate moral-legal, reclamando un papel activo como médico frente a «la arbitrariedad de aquellos jueces rutinarios, que por su educación, falta de talento, instrucción y estudios no pueden hacerse superiores a las preocupaciones vulgares.» Además, exigió altos estándares de profesionalidad a sus compañeros de profesión. Instaba a sus colegas a no presuponer que una mujer «seducida» era automáticamente capaz de infanticidio. Su visión de feminidad - de la mujer como «honesta, débil, crédula y engañada que se rinde a las hostigaciones del seductor»- y de maternidad («lo que el Criador ha puesto en corazones de todas las mujeres, el amor tierno a la criatura de sus entrañas») le permitió argumentar que era mucho más probable que la muerte del bebé fuera natural que inducida por el acto criminal de la madre, aunque esta fuera soltera. Desde esta posición, invitaba a las autoridades a la cautela y al rigor extremo en pro de la madre, por muy soltera que fuese ${ }^{23}$.

Esta actitud que, sin llegar a justificar a las madres solteras, las veía como merecedoras de un trato prudente y riguroso por parte de las au-

${ }^{21}$ Sobre la evolución compleja de los discursos y leyes concernientes a los «hijos naturales» en Francia: Bloquet, 2012.

${ }^{22}$ Décadas médico-quirúrgicas, Tomo I, N IV (1820-1821), pp. 164-173.

23 Ibid. 
toridades, preparó el terreno para propuestas explícitamente orientadas hacia la intervención social, que se podía interpretar en términos tanto de apoyo, como de control institucional. Un caso concreto de los años 1850 nos proporciona la oportunidad de observar la pugna dentro de las élites por definir las esferas privada y pública (en este caso: un asunto de honor familiar versus un problema social) y legitimar nuevos modos de intervención. En 1859, El Siglo Médico, una de las revistas médicas españolas más difundidas y prestigiosas, de tendencia más bien conservadora, se opuso al afán del gobernador civil de Soria de buscar índices de embarazo en mujeres solteras y viudas. Aparentemente, el gobernador civil pretendía organizar la protección de las madres solteras y viudas, para que pudieran dar el niño en adopción y no se supieran sus nombres, lo cual tenía dos propósitos principales: evitar los infanticidios y prevenir que ellas cayeran en la prostitución o se suicidasen. El autor del artículo sobre el tema muestra su indignación con tal propuesta: «¿Cómo se meterán en tales indagaciones sin ofensa del honor de solteras y viudas? [...] no hay más modos de evitar ese escándalo que la religión y la influencia de la autoridad paterna. ¿Qué derecho hay en fin en autoridad alguna para mezclarse en asuntos de esta naturaleza?» ${ }^{24}$.

La argumentación muestra que en aquella época existía un conflicto incluso a la hora de identificar este asunto en términos de un problema social, lo que implicaba que la intervención pública en estos ámbitos era altamente contestada. Por una parte, está la tendencia conservadora de plantearlo en términos de pecado y honor familiar, y, como tal, dejar a la familia y a la Iglesia que se ocupasen de crear un ambiente hostil que desincentivara tal comportamiento (incluida la negación de sepultura a las «deshonradas» que se suicidasen), mientras que el sistema judicial solo debiera intervenir para castigar duramente a las supuestas infanticidas. Por otra parte, los promotores de la reforma social reclamaron mayor protección para las mujeres seducidas, no solo por el bien de sus hijos «inocentes», sino también por el bien de ellas y de la sociedad (que no cayeran en la prostitución o alguna actividad criminal). Este caso muestra claramente la complejidad del liberalismo decimonónico y los peligros de leer de forma moralizante la crítica foucaultiana de la gubernamentalidad moderna. La autoridad compasiva con las madres solteras proponía fomentar

${ }^{24}$ El Siglo Médico, 1859, pp. 67-68. 
la intervención estatal en lo que se podía entender dentro del discurso liberal de la época como «la vida privada de las personas», para proteger a las mujeres del hostigamiento por parte de sus familias y comunidad. Asimismo, los argumentos conservadores de familia y religión se usaron para impedir la intervención de los representantes del Estado en la vida de las personas, de forma que se podía interpretar en términos de libertad por este mismo discurso liberal.

\section{Las virtudes de la soltería laica}

El discurso que ponía la maternidad en el centro mismo de la feminidad ayudó a suavizar las actitudes hacia algunas solteras de dudosa virtud. Este discurso maternalista impactó de manera importante también en los círculos católicos, impulsando, al mismo tiempo, un rearme de la defensa de la soltería célibe, laica o eclesiástica. El caso de una figura de peso en la Iglesia católica española como Antonio María Claret, paradigma de una Iglesia antiliberal desde el punto de vista ideológico, muestra los cambios de tendencia en ciertos sectores de la Iglesia que progresivamente en el XIX, sobre todo en la segunda mitad, fueron tratando de dotar de una dignidad similar a la soltería religiosa que al matrimonio y la maternidad biológica, aunque compartían la visión mayoritaria del clero decimonónico sobre que el celibato era un estado más perfecto que el matrimonio ${ }^{25}$. Claret consideró que optar por una vía u otra era una decisión racional e individual, aunque la mujer la consultase con Dios, con el cura y con sus padres. Así se lo trató de inculcar a los niños, sin establecer una jerarquía clara entre soltería y matrimonio, ya que lo importante era lo bien que éstos se ejerciesen: «el que mejor cumpla sus deberes, ora sea en el estado de célibe, ora en el de casado, será el que merecerá los aplausos de Dios, que la dará su premio, aunque acá abajo se tenga por menos excelente el uno que el otro.» ${ }^{26}$ En otros puntos de su relato, sin embargo, Claret situó el celibato virtuoso por encima del matrimonio, que se seguía considerando por la mayoría de eclesiásticos y periodistas, escritores y políticos católicos que se interesaron por estas cuestiones como el estado más digno de $\operatorname{todos}^{27}$.

\footnotetext{
25 Salomón, 2018,p. 106; Mínguez, 2018, p. 44.

${ }^{26}$ Claret, 1848 , p. 378.

27 Ibid., p. 380.
} 
En este contexto del maternalismo pujante, para defender el celibato como una opción no solo digna, sino hasta superior al matrimonio, los pensadores eclesiásticos ya no pudieron limitarse al uso de argumentos bíblicos y morales, sino que se vieron obligados a entrar en polémica con los argumentos en contra articulados dentro del discurso sobre la salud y la naturaleza humana, inscribiendo forzosamente su razonamiento en el discurso de la ciencia. Esta necesidad se aprecia particularmente en el último tercio del siglo XIX. Así, por ejemplo, el religioso José Taronjí y Cortés afirmaba:

La persona soltera, dice, anda solícita de las cosas del Dios, y busca el modo de agradarle. Pero el casado anda solícito de las cosas del mundo, y busca el modo de agradar a su mujer, y está dividido. La mujer no casada y la virgen piensan en Dios para santificarse en el cuerpo y en el espíritu. Pero la casada piensa en lo del mundo, y en la manera de agradar a su marido. La virginidad, o estado de soltería según Dios, no es contraria a la naturaleza humana, y el hombre, ayudado de la gracia, puede resistir las seducciones de la carne y contenerse en el deber. El celibato en este sentido favorece la salud y alarga la vida del individuo, modera los ímpetus de las pasiones y edifica la sociedad. Así lo afirma la ciencia $[\ldots]$ y así lo comprueba la experiencia de siglos. ${ }^{28}$

Las mujeres de las congregaciones femeninas durante el siglo XIX supieron aprovechar las potencialidades que ofrecía el modelo de feminidad católico defendido por la Iglesia y por las pensadoras y los pensadores católicos. Estas mujeres, que consagraron su vida al servicio de Dios, disfrutaron de grandes libertades en comparación con sus contemporáneas. Sin embargo, la entrada en los conventos para ordenarse monja era costosa, por lo que su ocupación fue posible sobre todo para mujeres provenientes de las familias pudientes. Durante esta centuria también aumentó el número de mujeres que actuaron como misioneras. Éstas obtuvieron así un amplio espacio de libertad y de promoción personal y de reconocimiento social ${ }^{29}$.

Mientras que la soltería religiosa seguía siendo alabada e incentivada en tal que un ideal loable y exigente, las solteras laicas sufrieron cierta estigmatización por parte de los eclesiásticos. Sobre todo, durante la primera mitad del XIX, los eclesiásticos mantenían que las mujeres solteras eran más susceptibles de caer en la tentación por estar acostumbradas a una re-

${ }_{28}^{28}$ La Cruz, 6-1886, p. 271.
${ }_{2}$ Mínguez, 2015, p. 402. 
lativa autonomía y amplia vida social ${ }^{30}$. Taronjí y Cortés defendió que el celibato era el más puro de todos los estados. Sin embargo, estableció una clara diferencia entre el celibato religioso y «ese celibatismo forzoso que algunos observan por no contraer las obligaciones del matrimonio y para entregarse con mayor libertad a la satisfacción de sus liviandades. Esa soltería calculada y procaz es [...] un mal terrible que debería desaparecer de nuestra sociedad» ${ }^{31}$. Con los mismos fines publicó un/a autor/a, desde el anonimato, un artículo sobre la idea entre una soltería buena y otra perjudicial. Partiendo la base de que «El matrimonio cristiano, es la institución más santa, porque santa es la religión que le proclama», se aseguró que el matrimonio y sus valores se veían diezmados por las doctrinas que fomentaban ciertos tipos de celibato: «Hablamos de celibato, no de ese celibato digno y santo que observa el sacerdote que por su ministerio debe ser un tesoro de pureza [...]. Hablamos de ese otro celibato que proclaman muchos [...] pintando con horripilantes colores las consecuencias del matrimonio [...] $\gg^{32}$. Hasta Concepción Arenal, una de las defensoras más influyentes de la soltería laica, habló de «un tipo de mujer soltera, ciertamente poco recomendable. Egoísta, extravagante» ${ }^{33}$.

Defender la soltería laica como una opción digna suponía una negociación compleja que requería expulsar de este modelo todo lo que lo dejara abierto a la ridiculización, muy habitual en la opinión pública de la época ${ }^{34}$. Fueron sobre todo las mujeres las que articularon una defensa vigorosa de la soltería laica frente a las sospechas y ridiculización. La presencia de las voces femeninas en este debate nos debe hacer reflexionar sobre la importancia que tuvo en la actividad pública de estas pensadoras su afán por ensanchar y dignificar su propio espacio de maniobra en tal que mujeres. En esta negociación al filo de la navaja integraron elementos de la apología del celibato enraizada profundamente en el discurso católico con los elementos liberales de libertad individual, utilidad y bien común. Concepción Arenal defendió la soltería virtuosa alegando la contribución de las solteras al bien común: «No es necesario que la mujer soltera haga votos ni vista un hábito para que su vida se consagre al bien de los demás» 35 :

\footnotetext{
30 Mínguez, 2016, p. 396.

31 La Cruz, 6-1886, p. 270.

32 Adelante, 7-3-1867, pp. 1-2.

33 Arenal, 1869, pp. 107-108.

34 El balear, 15-12-1853, p. 2.

35 Arenal, 1869, p. 109.
} 
En el mundo moderno, en los pueblos civilizados, los hombres se multiplican con sobrada rapidez, el exceso de población se hace sentir con frecuencia, no son madres lo que falta, y la mujer pura y benéfica que se dedica á hacer bien á sus semejantes, que como no hace falta á nadie está pronta á sacrificarse por todos [...], que forma su familia de aquella parte del género humano que sufre y la necesita, y que usa de su libertad haciéndose esclava de las santos deberes que se impone; esta mujer es tan respetable y tan útil como la mejor de las madres. ${ }^{36}$

Conforme con las expectativas de que a una mujer el amor al próximo le motivaba aún más que los valores abstractos de la patria, la defensa de la soltería laica podría asimismo poner en valor el sacrificio de la soltera por su familia:

Elvira no se había querido casar por no querer dejar a su madre en una gran soledad moral: soltera y libre, partía las penas y los cuidados de aquella madre infeliz; casada, se hubiera dedicado por completo a su esposo y a sus hijos; optó, pues, por no casarse, y dio a su madre con esto la prueba más grande y más elocuente de su amor. ${ }^{37}$

Además, dentro del discurso muy extendido en la época, que construía a las mujeres que habían recibido una educación moral adecuada como más capaces de contención sexual, mantenía que - a diferencia de los hombres solteros - una mujer soltera dedicada al bien común o al cuidado de sus próximos no estaba en peligro de caer en el vicio, si su situación económica no le empujaba a ello. De paso, las intelectuales españolas articularon una defensa del ensanchamiento de la esfera laboral para las mujeres, vinculando el acceso a las profesiones liberales y a los puestos de trabajo asalariado con el fomento de la virtud femenina. «La mujer soltera, casta si tiene un poco de pan y un poco de educación, no es, como el hombre célibe, un elemento de vicios, desórdenes y males, sino que por el contrario, puede consagrar toda su existencia al bien de la sociedad» ${ }^{38}$

En esta línea argumentativa, la defensa de la soltería integró en el siglo XIX el argumento liberal que ponía énfasis en la libre voluntad y

\footnotetext{
36 Arenal, 1869, p. 110.

37 Sinués, 1890, pp. 96-97.

38 Arenal, 1869, pp. 107-108.
} 
falta de intereses materiales como bases de un matrimonio deseable en el que se podía establecer armonía jerárquica entre esposos, construida sobre el dominio sentimental ${ }^{39}$. Desde América, pasando por Francia y Austria, hasta Rusia y el Imperio otomano, el discurso transnacional desplegado en novelas, obras de teatro, reformas jurídicas y tratados moralizantes denunciaba como indigno el matrimonio forzado o contraído por «malas» razones. La crítica de la intervención paterna en la vida de los hijos adultos se enmarcaba en la deslegitimación de la autoridad del padre frente a la libertad individual de los hermanos, dentro del cuestionamiento del Antiguo Régimen por el constitucionalismo. Por otra parte, la denuncia del matrimonio como negocio, como la única opción frente a la pobreza, no solo reivindicaba el principio de la libertad individual, sino que se inscribía en un discurso de reforma social, que entendía matrimonios infelices como fuente potencial de todo tipo de problemas sociales. En este contexto, la soltería virtuosa aparecía como una opción más digna y responsable que un «mal matrimonio».

Sin embargo, las defensoras de la soltería tuvieron que enfrentarse al imaginario social, que, al margen del discurso eclesiástico, presentaba el matrimonio como el signo máximo del éxito de una mujer. Al mismo tiempo que reivindicaron la dignidad de la soltería poniendo énfasis en su altruismo y falta de cálculo materialista, se vieron claramente interpeladas por el discurso que ridiculizaba a las mujeres solteras mediante referencias a su fracaso en el mercado matrimonial, a su falta de deseabilidad. Esta ridiculización no construía la soltería como transgresora ni punible, sino que, vinculándola a la fealdad, la situaba por debajo del matrimonio en la jerarquía de prestigio de la feminidad respetable. Esta operación además dejaba en las manos de los hombres la posición de las mujeres dentro de esta jerarquía, al ser ellos los que tenían el poder de decidir, otorgando a la mujer respetable el patente de la deseabilidad honrosa al casarse con ella. Las mujeres solteras de esta época se mostraron muy interpeladas por esta práctica de ridiculizarlas como feas y no deseadas; podemos observar cómo insistían una y otra vez en que habían tenido pretendientes, en que se quedaron solteras por su propia decisión y no por falta de oportunidades ${ }^{40}$.

\footnotetext{
39 Martykánová, 2017, pp. 166-168.

40 Mínguez, 2016, p. 400.
} 


\section{La reformulación de la soltería en el primer tercio del siglo $\mathrm{xx}$}

En la Encíclica Rerum Novarum (1891), que fue referencia en muchos aspectos para el movimiento católico de finales del XIX y principios del Xx, se estipulaba, para ambos sexos, que «en la elección del género de vida, está en la mano y en la voluntad de cada cual preferir uno de estos dos: o seguir el consejo de Jesucristo sobre la virginidad o ligarse con el vínculo matrimonial» ${ }^{41}$. A pesar de esta afirmación papal, en el pensamiento de los intelectuales eclesiásticos hubo una pugna para establecer una jerarquía entre los modelos de feminidad, lo que confirma, como ya hemos visto, que el orden jerárquico entre las distintas vías aprobadas como virtuosas por la Iglesia no era estable. Por un lado, hubo quienes se apoyaron en el discurso eclesiástico tradicional para sostener la idea de la primacía de la soltería sobre el matrimonio. Por otro lado, las prácticas sociales y culturales no se regían por la cúpula eclesiástica, y en la práctica social el matrimonio estaba más valorado que la soltería. En consecuencia, hubo intelectuales católicos que priorizaron el matrimonio sobre la soltería. A esto hay que sumar que muchos de los católicos estuvieron profundamente influidos por el discurso liberal y socialista, sobre todo en su vertiente anticlerical, que feminizaba a los curas y ridiculizaba a las solteras laicas ${ }^{42}$.

Por ejemplo, un referente del movimiento católico femenino, el Padre Graciano Martínez, aseguró que las mujeres tenían en la maternidad «el papel más principal que les asigna la naturaleza», sin embargo, había algunas mujeres llamadas «a más alta perfección». La explicación de lo que entendía por «alta perfección» es la siguiente: «no incluyo solamente las vocaciones al claustro, sino también las vocaciones a la soltería con objeto de consagrarse más ampliamente al bien del prójimo ${ }^{43}$. Asimismo, mientras para el capuchino Ambrosio de Valencina «La virginidad y el celibato católico [...] es un estado, no sólo igual al matrimonio, sino superior, y mucho más perfecto ${ }^{44}$, para Concepción Gimeno de Flaquer, que tanta influencia tuvo en las primeras décadas del siglo XX: «La solte-

41 http://w2.vatican.va/content/leo-xiii/es/encyclicals/documents/hf_l-xiii_ enc_15051891_rerum-novarum.html Consultado a 5 de febrero de 2019

${ }^{42}$ El discurso anticlerical y médico durante el primer tercio del siglo XX en España articuló gran desprecio por las solteras: Aresti, 2001, pp. 112-113 y p. 170.

43 Martínez, 1921, pp. 331-332.

44 Valencina, 1897, pp. 303-304. 
rona es un ser más útil a la sociedad de lo que se cree. La solterona, como no tiene hijos, ni marido, que son los seres que más absorben nuestra vida, se consagra a cicatrizar los dolores de la humanidad; para ella, su familia es la gran familia humana» ${ }^{45}$.

Activistas como Dolors Monserdá, una referencia del feminismo católico catalán, buscaron destacar los beneficios que las labores religiosas, sociales y familiares de las solteras tendrían para la sociedad ${ }^{46}$. Del mismo modo, la terciaria franciscana María de Echarri afirmaba que Dios y la Iglesia ensalzaban y protegían a las mujeres independientemente de su estado y que «En la antigüedad [...] las que no se casaban, se creían degradadas, perdida su dignidad y no se les ocurría consolarse ensalzando muy alto el privilegio de la virginidad; esta nobleza la proclama el Cristianismo [...]. Esto no significa en manera alguna depreciación para la mujer casada» ${ }^{47}$.

Esta idea, como ya hemos mostrado, estuvo muy extendida en la época que abarca este estudio. Echarri plasmó en sus novelas y cuentos su posicionamiento sobre la tercera vía: la soltería laica virtuosa para hacer el bien en el campo social, católico y caritativo/benéfico. Por ejemplo, en El que siembra con lágrimas... (1927), cuando una joven confiesa a su amiga virtuosa que desea quedarse soltera y dedicarse al apostolado social, esta le responde: «Dices que te tira la vida de soltera, pero no de esas solteras egoístas que sólo piensan en sí [...]. Vida de soltera..., para darse al apostolado, me dices. Bien, Elena... Haces bien [...]. Se vive la vida del Divino Maestro» ${ }^{48}$.

En este período, por tanto, continuó la lucha por reafirmar y fortalecer la idea de la soltería femenina como un estado igual o más digno que el matrimonio. Sin embargo, hubo muchos intelectuales católicos que estuvieron preocupados al percibir que había unas altas tasas de soltería en España en comparación con otros países del entorno ${ }^{49}$. Esta inquietud generó debates y posiciones encontradas. Para algunos autores, el problema deri-

45 Gimeno de Flaquer, 1887 [1882], p. 47.

46 Monserdá, 1909.

47 Echarri, 1908, pp. 8-9.

48 Echarri, 1927, p. 24. Echarri prologó una obra que biografió a un grupo de católicas destacadas que se presentaron como ejemplares y que, en muchas ocasiones, debieron imponer a sus familiares el deseo de quedar solteras para dedicarse en exclusiva a su devoción religiosa y/o a la práctica de la caridad: Holl, 1923.

${ }^{49}$ El porcentaje de solteras en España aumentó entre 1900 y 1930 de un 29,50\% a un 33,32\%: Aguado y Ramos, 2007, p. 277. 
vaba de que muchos hombres (menos virtuosos y cristianos que las mujeres) no creyesen en el matrimonio cristiano ni en su indisolubilidad. Esta situación provocaba que «muchas mujeres virtuosas prefieran una soltería digna y cristiana $»^{50}$. De hecho, como ha mostrado Miren Llona, hubo mujeres que, sin ser particularmente religiosas, al percibirse como personas más virtuosas que los hombres, optaron por el celibato como una opción más digna que la del matrimonio. Tomaron estas decisiones a pesar de que en la mayoría de las culturas políticas prevalecía en la época la noción de que la auténtica realización de la feminidad se producía a través de la maternidad ${ }^{51}$. Por tanto, para entender estos posicionamientos hay que tener presente la redefinición laica de la soltería digna. Otros trasladaron la culpa de las altas tasas de soltería en España a las mujeres, afirmando que los hombres se veían forzaros a la soltería por la frivolidad de estas ${ }^{52}$. Ambos posicionamientos, en los que las culpas recaían sobre el conjunto de los hombres o de las mujeres, quedan reflejados en Memorias de un solterón (1896) de Emilia Pardo Bazán, obra en la que, al principio de la trama, ni el protagonista ni la co-protagonista están dispuestos a casarse ${ }^{53}$.

Ante el gran número de solteras en España, buena parte de ellas laicas, muchos autores católicos buscaron establecer una diferencia tajante entre la soltería laica digna y la indigna. El hincapié en la posibilidad de vivir la soltería laica de forma digna, igual de valiosa que la religiosa, era algo importante para las muchas solteras forzosas que deseaban casarse, pero que no lo conseguían. Entonces, estas solteras debían cambiar la mentalidad y, para mantener su dignidad, tenían que abrazar los principios de la soltería virtuosa, es decir, convertirse en «virtuosas porque no pueden ser otra $\cos a{ }^{54}$.

En el primer cuarto del siglo Xx, matrimonio y castidad fueron dos conceptos clave en el discurso católico sobre la sexualidad, que era altamente exigente con mujeres y hombres, al imponer un modelo de contención difícil de cumplir. La Iglesia defendía que los verdaderos creyentes solteros deberían practicar la abstinencia sexual total y que en los matrimonios las relaciones debían tener la procreación como finalidad ${ }^{55}$. Así lo

\footnotetext{
50 Noticiero extremeño, 2-6-1906, p. 3; La Independencia, 28-11-1912, p. 2.

51 Llona, 2007, pp. 95-96

52 El Guadalete, 10-10-1890, p. 2.

53 Pardo Bazán, 1896, p. 7 y 81.

54 Acosta, 1926, p. 335.

55 Aresti, 2002, p. 127.
} 
expresaba el jesuita Ramón Ruiz Amado: «La paz y la felicidad que en el matrimonio [...] han de ser fruto de la castidad y dominio de los apetitos sensuales [...]. Sólo la virtud de la castidad, que sujeta la concupiscencia del joven soltero, puede ser la que ordene sus manifestaciones en la vida matrimonial. ${ }^{56}$ No obstante, la sociedad era mucho más permisiva con los excesos masculinos que con los femeninos e, incluso, hasta los fomentaba.

La defensa del carácter sacramental del matrimonio que hizo la Iglesia católica no implicó que el modelo de madre biológica fuese necesariamente considerado como superior. Por tanto, si bien el arquetipo de «la solterona» pervivió renovado, y la crítica a la soltería fue una de las formas más recurrentes para ensalzar el matrimonio y la maternidad, creemos que la estigmatización debemos entenderla, sobre todo, como un mecanismo para establecer una jerarquía de prestigio entre los modelos de feminidad aceptables ${ }^{57}$. La Iglesia española percibió el matrimonio principalmente como una estructura eficaz para el control de la vida de las personas, reforzando así el orden social, moral y sexual y, de paso, los intereses que tenían los jerarcas eclesiásticos en cuanto que solteros ${ }^{58}$. Esto no quiere decir que sus planteamientos fuesen aceptados por el conjunto de la sociedad, ni siquiera entre los católicos, muchos de los cuales estaban influidos por los discursos liberales y socialistas. La pluralidad y la tensión por la jerarquización de los modelos de feminidad fueron constantes en el periodo.

Los debates en torno de los modelos de feminidad no fueron algo exclusivo de los activistas católicos. De esta forma tan perspicaz expresaba Carmen de Burgos la complejidad de estas tensiones y contradicciones:

Las costumbres están también en pugna con las disposiciones del Código. Este da mayores derechos a la mujer soltera o viuda que a la casada, y en cambio, en la vida social la casada goza de mayor libertad. El casamiento es como un ascenso en la categoría social y la mujer adquiere más libertad en las costumbres. La sociedad es más benévola y tolerante con la mujer casada cuya moral es dudosa que con las jóvenes solteras..$^{59}$

56 Ruiz Amado, 1954 [1930], p. 74.

57 Algunas de las críticas del periodo: La correspondencia de Valencia, 14-11-1930, p. 3; El Día de Palencia, 21-2-1927, p. 1.

58 Aresti, 2002, p. 129.

59 Burgos, 1927, p. 136. 
Asimismo, las teorías médicas y científicas del siglo XIX, se reelaboraron y siguieron enriqueciendo el debate sobre la soltería, el matrimonio y la maternidad. Como muestra Nerea Aresti, «la clase médica» intervino activamente en los esfuerzos por proteger y, hasta cierto punto, dignificar a las madres solteras, de forma mucho más contundente que los tímidos intentos que observamos a mediados del siglo XIX ${ }^{60}$. Además, la maternidad fue, junto con el coito, la clave en la argumentación de que el matrimonio fuera mejor para la salud que la soltería, tal y como postulaba, por ejemplo, el médico e historiador de la medicina Luis Comenge y Ferrer (1854-1916), en continuidad con los debates desarrollados ya en los 1820:

Estas desventajas médicas [como el histerismo o la neurastia], adherentes a la soltería, ponen fuera de discusión la excelencia salubre del casamiento, reforzada con saber que las dolencias histéricas y cancerosas, los desarreglos gástricos crónicos, el esplín y otras manifestaciones patológicas, muestran preferencia por los solteros.

Sabido es que el casado engorda y mejora, por lo regular, y que las funciones de la maternidad prestan a la mujer nuevos encantos y una segunda juventud que se opone a que los años ajen y marchiten sus bellos trazos, como sucede en las solteronas.

Gran medicina social es la boda, no hay duda ${ }^{61}$

Estos planteamientos cuajaron también en el pensamiento republicano y socialista, por lo que personas como la joven Hildegart (1914-1933) defendieron que sería positivo que los clérigos pudiesen formar una familia puesto que «el celibato impuesto a religiosos y clérigos ha producido efectos deplorables» ${ }^{62}$. En estos sectores hubo amplia consciencia de que, en conexión con lo mencionado sobre Carmen de Burgos, la opción del matrimonio era más deseable por muchas mujeres no sólo por las connotaciones sociales y culturales, sino porque estas (debido a su falta de educación y formación) viesen en el matrimonio la única forma de manutención. Muchas novelas de la época giraron en torno de este problema, como la Trampa del Arenal de Margarita Nelken (1923) ${ }^{63}$. Incluso hubo interpretaciones que ponían énfasis en las consecuencias que sufrían mu-

\footnotetext{
60 Aresti, 2001, p. 167-168.

${ }^{61}$ Comenge y Ferrer, 1920 [19s/f], p. 70.

62 Hildegart, 1931, p. 27.

${ }^{63}$ Nelken, 1923.
} 
Alejandro Camino, Darina Martykánová

chos hombres por esta situación, al ser engañados por quienes estaban desesperadas por casarse:

Lo que si debo negar [...] es que educar a la mujer para que pueda vivir independiente y libre, sea inmoral; lo inmoral es educarla para esposa, en primer lugar, porque se corre el riesgo de hacerla la víctima de un engaño si el matrimonio no se realiza, y en segundo lugar, porque no ofreciendo a la mujer más horizonte que el matrimonio, apelará a toda clase de medios para casarse, engañará inicuamente al hombre en quien adivine una posibilidad de marido, fingiendo un amor que no sienta. ${ }^{64}$

Sin bendecir la soltería, estas personas cuestionaron que el matrimonio fuese la única opción digna. En sus planteamientos influyó, por un lado, la crítica liberal del matrimonio forzado, aunque fuera por circunstancias materiales, $\mathrm{y}$, por otro lado, los planteamientos socialistas sobre el amor libre, coincidiendo ambas corrientes políticas en la mezquindad del matrimonio por interés, incompatible con la verdadera libertad del individuo. Como vemos, la opinión de la Iglesia sobre la soltería no era la única que influía sobre las mujeres católicas, por lo que para muchos católicos la jerarquía de prestigio entre el matrimonio y la soltería no estaba clara. Incluso, hubo líderes del movimiento católico femenino del primer tercio del siglo XX que permanecieron solteras y otras que contrajeron matrimonio. Para mujeres activistas como Juana Salas, Dolores de Gortázar o Carmen Velacoracho casarse no fue impedimento para sus actividades, porque resultaba aceptable socialmente que una mujer estuviese casada y su marido aceptase que tuviese una participación en la vida pública. Según contó Velacoracho, ella sólo aceptó casarse cuando su pretendiente le prometió que le secundaría en su lucha por conseguir que las mujeres obtuviesen los mismos derechos que los hombres ${ }^{65}$.

Uno de los principales objetivos de las mujeres implicadas en el movimiento católico femenino, estuviesen casadas o solteras, fue cuestionar los matrimonios irreflexivos y sus consecuencias negativas. Defendieron que ese estado no debía ser el único destino para las mujeres, sobre todo porque, siguiendo a la crítica feminista que se fue desarrollando desde la Ilustración, consideraban que estos enlaces eran crueles e implicaban

64 Vida Socialista, 25-9-1910, p. 7.

65 Aspiraciones, 24-11-1934, p. 4. 
la «esclavitud» para las mujeres ${ }^{66}$. Por estos motivos, algunas católicas como Velacoracho (1918) o Francisca Bohigas (1929) defendieron que el matrimonio por «amor» era el único virtuoso posible, puesto que era mejor no casarse que hacerlo con un hombre poco deseable:

Perjudica en grado sumo para la dicha en el matrimonio el estado de inferioridad en que la mujer se encuentra [...]. Como no puede mandar de igual a igual, aprieta las cadenas únicas por las cuales puede dominar al hombre, las de la coquetería [...]. Otórguensele los derechos a la mujer, y $[\ldots]$ : no teniendo que casarse por necesidad se casará por amor. ${ }^{67}$

Y si conseguimos algún día que la mujer en lugar de confiar la solución de su vida al matrimonio, cuente con un arte, oficio o carrera, que le permita ganarse [...] la vida cuando le sea preciso también irá al matrimonio, pero irá por afecto, por interés moral por deseo de crear una familia, y sin apremio económico viéndose libre del deber de enamorarse del primero que le dirija la palabra. ${ }^{68}$

\section{Primer franquismo, una coyuntura especial}

El primer franquismo es el período para el que existen más investigaciones sobre esta cuestión, aunque los mitos sobre la soltería perduran. Hasta en trabajos sólidos es frecuente encontrar afirmaciones acerca de cómo esta no era aceptada durante el franquismo como una opción y estaba mal vista ${ }^{69}$, lo que, en nuestra opinión, homogeniza la multiplicidad de modelos de feminidad y la jerarquía de prestigio inestable entre ellos. Es cierto que el modelo oficial de género durante la década de 1940, cuando el falangismo tenía gran peso, ensalzó la maternidad y buscó estigmatizar los otros estados, defendiendo que el deber patriótico y religioso de las mujeres consistía en ser buenas esposas y madres. Sin embargo, esto tuvo lugar en la coyuntura de una crisis demográfica provocada por la guerra y en un contexto internacional de políticas pro-natalistas, considerándose una prioridad nacional que las mujeres se casasen y tuviesen descendencia. En la propaganda del régimen y en muchos manuales de conducta afi-

\footnotetext{
66 Para una perspectiva transnacional: Miller, 2017; Malečková, 2002.

67 Real Biblioteca, Signatura: VIII/1810: Aspiraciones: 29 de junio de 1918.

68 Diario de León, 24-9-1929, p. 1. De la misma opinión fue más de medio siglo antes Concepción Arenal: Arenal, 1869, p. 67.

69 Monlleó, 2, 1999, p. 154; Peinado, 2012, p. 51; Morcillo, 2015, pp. 117-118.
} 
Alejandro Camino, Darina Martykánová

nes se estigmatizó a las solteras como egoístas, frívolas y estrafalarias. Sin embargo, se trató más de un mensaje propagandístico que de un oprobio practicado en la vida cotidiana que buscase acabar con las solteras, por lo que no se subvirtió, especialmente en aquellas personas católicas no falangistas, la jerarquía de modelos aceptables de feminidad.

En los primeros años del régimen, como los rasgos del modelo oficial de género del franquismo no estaban consolidados, convivieron de forma tensa elementos provenientes del falangismo y del catolicismo, que estuvieron en pugna por redefinir y articular el discurso de género oficial. En esta coyuntura especial, la estigmatización de la soltería provenía más bien del falangismo, puesto que a las solteras las definió como débiles y frágiles que no habían luchado lo suficiente por llegar al matrimonio. Por lo tanto, una vez que el proyecto por el que apostaron los falangistas colapsó con la derrota del Eje en la Segunda Guerra Mundial, el catolicismo fue imponiendo progresivamente sus pautas de mujer y hombre ideal. Las interpretaciones que consideramos erróneas se deben a que, como en el discurso oficial en España la soltería fue criticada y considerada menos deseable que en otros períodos de la historia contemporánea española, se interpretó que esta era rechazada y no se consideraba digna. En nuestra opinión, esta fue una estrategia del régimen para subordinar simbólicamente a unas mujeres necesarias, pero potencialmente peligrosas, para propiciar que estas se esforzasen en mantener una reputación inmaculada por el miedo a ser estigmatizadas, así como para que el número de solteras voluntarias no se disparase ${ }^{70}$.

Para Ángela Pérez del Puerto, el movimiento católico seglar femenino reconocía a las mujeres, todavía en los años cuarenta, tres caminos socialmente aceptables por los que podía discurrir su vida, siendo uno de ellos la soltería laica femenina. Este punto era compartido por el movimiento católico mundial. Mientras, las falangistas sólo establecían dos posibles destinos para la vida de una mujer: el matrimonio y el convento, por mucho que la soltería civil fuese inevitable en algunos casos por la coyuntura $^{71}$.

70 Para algunas de las estrategias y argumentos de la Sección Femenina de Falange en sus revistas para lograr estos objetivos: Barrera, 2019, pp. 240-241. Sobre la tensa convivencia entre los elementos provenientes del falangismo y el catolicismo: Saz, 2003. Para un trabajo que ponga en perspectiva las diversas identidades de género que hubo durante el franquismo, véase el dossier número 37 de Historia y Política: Cenarro, 2017.

${ }^{71}$ Pérez del Puerto, 2015, pp. 5-6 y 349-350. 
De forma similar a lo que hemos mostrado en los periodos anteriores, para los católicos españoles si una mujer hacía voto de soltería, para que esta fuese digna debía practicar las virtudes supuestamente naturales de las mujeres en vez de en el hogar, en la «esfera pública» o en beneficio de otros miembros de su familia. Para diferenciar a estas solteras de las antiideales y/o de las que estaban privadas de respetabilidad, se establecieron distinciones entre tres tipos de soltería: quienes optaban voluntariamente por la soltería y desplegaban unas prácticas virtuosas, quienes no llegaban a casarse por motivos ajenos a su voluntad (estas no fueron criticadas por la Iglesia siempre que actuasen siguiendo los preceptos establecidos para las solteras respetables) y, por último, quienes optaron por ese estado para no cumplir los deberes que el matrimonio imponía, pero sin estar dispuestas a comportarse como se pedía a las solteras dignas y virtuosas. La jerarquía eclesiástica trató de estigmatizar a estas últimas.

Durante el proceso de fricción entre el pensamiento católico y el falangista por definir en un sentido o en otro la soltería dentro del discurso oficial del régimen franquista, creemos que es relevante la actuación y el pensamiento de Francisca Bohigas. Esta mujer, que pertenecía al grupo reducido de líderes que moldearon el pensamiento católico durante el periodo anterior, se mantuvo adscrita fundamentalmente a la cultura política católica. Gozando de una posición privilegiada, Bohigas tuvo la suficiente autonomía para cuestionar y/o resistir públicamente algunas de las propuestas de género de la Sección Femenina de Falange (SF) con las que no estaba de acuerdo.

Bohigas hizo un esfuerzo para que ciertos tipos de soltería mantuviesen (o, mejor dicho, recuperasen) la dignidad y la aceptación social que tradicionalmente habían tenido en España. Con este objetivo presentó la soltería como algo que debía ser no solo aceptable, sino respetable, porque todas las mujeres eran sujetos dignos siempre que siguiesen los postulados católicos. Consideraba la soltería consciente, si se salvaguardaban los criterios del honor y de la respetabilidad femenina, una opción tan digna como el matrimonio, por lo que tenía que ser respetado si una mujer se quedaba soltera de forma voluntaria (como era su caso) ${ }^{72}$. Asimismo, recomendaba a las mujeres que habían deseado casarse, pero no habían podido, independientemente del motivo, que se entregasen de forma total a una tarea social y al cuidado de familiares para que no fuesen asociadas

72 Bohigas, 1941, pp. 118-122; Camino, 2018, pp. 232-233. 
a los estigmas negativos de las solteronas o solteras egoístas ${ }^{73}$. La cuestión de la dignidad era central en el intento de Bohigas de recuperar una tradición centenaria del pensamiento católico español.

La toma de postura explícita que sostuvo Bohigas en sus escritos sobre que era digno no casarse por decisión propia, se diferenciaba de la tan recurrente apelación a los efectos demográficos de la guerra que utilizaban muchas de las jerarquías de la SF para justificar su soltería durante los primeros años del franquismo ${ }^{74}$. Además, mientras estas criticaban y estigmatizaban la soltería laica, disfrutaban en la mayoría de los círculos sociales un estatus de dignidad como solteras dirigentes. Asimismo, las falangistas no justificaron la soltería laica femenina tanto por razones sociales o religiosas sino políticas. De todas formas, la soltería militante de estas mujeres normalmente no conllevó que viviesen de forma autónoma o independiente, puesto que permanecieron en la casa paterna o materna y continuaron realizando tareas de cuidado a padres, hermanos, sobrinos, etc. ${ }^{75}$. Esta contradicción entre vida práctica y discurso, tan repetidamente resaltada en la historiografía de género, no fue exclusiva de las mujeres militantes de este período, sino que caracterizó a la movilización femenina católica a lo largo del siglo $\mathrm{XX}^{76}$. Esto se debió a que existían otros caminos de construcción de la identidad(es) de las mujeres que no estaban basados en la maternidad biológica y en el matrimonio. En cualquier caso, como en todo el periodo analizado, la justificación de la soltería casi nunca parecía (poder) responder al deseo individual de las mujeres, sino que era presentada como un sacrificio consciente por otros, especialmente Dios, la comunidad nacional o la familia.

Bohigas también reivindicó que, si bien las niñas debían recibir una formación que las preparase para ser buenas madres y atender adecuadamente el hogar porque era una labor que solteras o casadas debían desarrollar para ser una «mujer con plena dignidad femenina» ${ }^{77}$, ante la mala situación económica del país había que formar a todas las jóvenes para ejercer una profesión, porque el trabajo no denigraba, sino que enaltecía. El objetivo era que todas las españolas pudiesen contemplar su futuro con

73 Bohigas, 1941, pp. 119-121.

74 Gallego, 1983, p. 106.

75 Blasco, 1997, p. 166.

76 Blasco, 2005, pp. 55-66. La contradicción que hubo dentro de la SF entre el discurso y la vida práctica de sus miembros, ha sido bastante estudiada: Barrachina, 1991, pp. 211-217.

77 Bohigas, 1941, p. 120 y p. 122. 
seguridad, sin verse forzadas «a un matrimonio de conveniencia ni a convertirse en una carga para los suyos ${ }^{78}$. Argumentos de este estilo habían sido utilizados frecuentemente por las feministas católicas desde finales del siglo XIX, ella incluida, para justificar el trabajo de las mujeres ${ }^{79}$, pero en la posguerra prácticamente nadie adoptó esta posición. Esto se debió a que contradecía el discurso oficial y la política del régimen franquista, que buscó mediante una amplia legislación en el ámbito laboral, especialmente el Fuero del Trabajo (1938), apartar a las mujeres, sobre todo a las casadas, del trabajo remunerado fuera del hogar. Por tanto, fue un proceso con claras continuidades y discontinuidades en el que, además, se hibrida lo nuevo (profesión) con lo tradicional (celibato digno).

Si dejamos el estudio en 1950 es precisamente porque, una vez que en España el catolicismo se impuso como cultura política dominante a pesar del poder educativo que mantuvo la Sección Femenina de Falange, sumado a la propia evolución del régimen dictatorial y a la petición de las católicas de que se ampliasen los campos de actuación de las mujeres en la sociedad y la Iglesia, se produjeron cambios en el modelo oficial de mujer. En este periodo se siguió defendiendo, aunque más claramente, por parte de las católicas que la maternidad (biológica o social) no era la única opción posible para las mujeres y se recuperó más explícitamente la idea de que las mujeres podían tener una vida completa y digna si eran solteras (religiosas o laicas), puesto que realizaban imprescindibles labores caritativas, profesionales (profesorado, enfermería, etc.), de apostolado o de ayuda familiar. Quizás el gran símbolo de este cambio fue la obra Nosotras, las solteras $(1959)^{80}$.

\section{A modo de conclusión}

Tradicionalmente, la soltería tenía un lugar bien establecido en el orden social y en la construcción del género en los países de la Europa cristiana, aunque las tasas de soltería femenina podían variar sustancialmente. En el pensamiento católico, el celibato religioso fue explícitamente defendido como una opción superior al matrimonio. En nuestra opinión, esta tradición centenaria seguía moldeando las posturas hacia la soltería femenina

\footnotetext{
78 Bohigas, 1947, p. 5. Véase, también, pp. 20-54 y p. 255.

79 Blasco, 2014, pp. 107-133; Llona, 1998, pp. 287-288.

${ }^{80}$ Salas, 1959.
} 
también en el siglo XIX y en la primera mitad del siglo XX, cuando aparecieron varios retos discursivos; ante todo, la creciente importancia de la maternidad en la definición de la feminidad a la vez útil y respetable, pero también la noción del amor libre. Si bien es cierto que muchos pensadores católicos interiorizaron el discurso de género que asociaba la feminidad a la maternidad, no pudieron negar la dignidad a la soltería «virtuosa», entendida la virtud femenina en términos de castidad, o contención sexual absoluta. Es más, sobre todo las mujeres situadas en la órbita del pensamiento católico incorporaron elementos del discurso liberal sobre el matrimonio basado en el amor y en la libertad para insistir en la dignidad de la soltería virtuosa frente a los matrimonios por interés o por necesidad.

La pluralidad se observa tanto en la práctica social, como en los discursos normativos a lo largo del periodo analizado. Incluso en los momentos de mayor presión a favor del matrimonio y de la maternidad biológica como el destino femenino por excelencia, como pudo ser el periodo de la guerra civil y del primer franquismo, la soltería se mantuvo como opción respetable y digna, siempre que se cumplieran ciertas condiciones, básicamente la contención sexual y la utilidad para la familia y/o para la sociedad. En términos generales, la jerarquía de los modelos de feminidad era inestable y existió una pugna permanente para definir no solo un ideal femenino, sino por ordenar jerárquicamente las distintas formas de ser mujer. Esta pugna, en la que participaron hombres y mujeres, se alimentó de los discursos como el eclesiástico y el médico e incorporó planteamientos católicos, liberales y socialistas, creando un espacio de maniobra para legitimar múltiples formas de ser una mujer respetable, incluida la soltería virtuosa.

\section{Bibliografía}

Acosta, José María de, Las eternas mironas: (la novela de la solterona), Renacimientos, Madrid, 1926.

Aguado, Ana y Ramos, Dolores, «La modernidad que viene. Mujeres, vida cotidiana y espacios de ocio en los años veinte y treinta», Arenal, 14, 2, 2007, pp. 265-289.

APETREI, Sarah, «Masculine Virgins: Celibacy and Gender in Late Stuart London», en APETReI, Sarah y SMIth, Hannah (eds.), Religion and Women in Britain, c.1660-1760, Routeledge, 2016, pp. 41-60.

Arenal, Concepción, La mujer del Porvenir, Oficina Tipográfica del Hospicio, Madrid, 1869. 
La soltería virtuosa: dignidad, utilidad y el discurso sobre el celibato femenino...

Aresti, Nerea, Médicos, Donjuanes y Mujeres Modernas. Los ideales de feminidad y masculinidad en el primer tercio del siglo $\mathrm{XX}$, Editorial de la Universidad del País Vasco, Guipúzcoa, 2001.

ARESTI, Nerea, «La nueva mujer sexual y el varón domesticado. El movimiento liberal para la reforma de la sexualidad», Arenal, 9, 1, 2002, pp. 125-150.

ARESTI, Nerea, «Cuestión de dignidad. Género, feminismo y culturas políticas», en Forcadell, Carlos, y SuÁrez Cortina, Manuel (coords.), La Restauración y la República: 1874-1936, Marcial Pons, Madrid, 2015, pp. 85-110.

BARRACHINA, Marie Aline, «Ideal de la mujer Falangista. Ideal Falangista de la Mujer», en VVAA, Las mujeres y la guerra civil española, Instituto de la Mujer, 1991, pp. 211-217.

BARrerA, Begoña, Mujeres bajo tutela: una historia de la sección femenina de falange desde el género y las emociones (1934-1977), Tesis Doctoral, Universidad de Sevilla, 2019.

Beauvalet-Boutouyrie, «La femme seule à l'époque moderne: une histoire qui reste à écrire», Annales de démographie historique, 2001, pp. 127-141.

Blasco, Inmaculada, Armas femeninas para la contrarrevolución: la SF en Aragón (1936-1950), Atenea, Málaga, 1997.

BLASCO, Inmaculada, «"Sección Femenina” y "Acción Católica”: la movilización de las mujeres durante el franquismo», Gerónimo de Uztariz, 21, 2005, pp. 55-66.

Blasco, Inmaculada, «Juana Salas (1875-1976): el feminismo católico», en CENARRo, Ángela e Illion, Régine (coords.), Feminismos: contribuciones desde la historia. Prensas de la Universidad de Zaragoza, Zaragoza, 2014, pp. 107-133.

BLOQUET, Josée, «La société n'a pas intérêt à ce que des bâtards soient reconnus», Napoleonica. La Revue 14, 2012, pp. 50-73.

BoHIGAS, Francisca, Hogar, Gráficas Reunidas, Madrid, 1941.

BoHIGAs, Francisca, ¿Qué profesión elegir? Guía de profesiones femeninas, Mayfe, Madrid, 1947.

BouSQUET, Jean-Baptiste, Du mariage considéré comme moyen préservatif et curative des maladies, París, 1820.

Burgos, Carmen de, La mujer moderna y sus derechos, Sempere, Valencia, 1927.

CAMINo, Alejandro, «Entre el hogar y la profesión: los manuales de conducta de Francisca Bohigas durante el primer franquismo (1939-1950)», Travessias, 12, 2018, pp. 224-242.

CenARro, Ángela (ed.), «Identidades de género en el catolicismo, el falangismo y la dictadura de Franco», Historia y Política, 37, 2017.

Claret, Antonio María, Catecismo de la doctrina cristiana: explicado y adoptado a la capacidad de los niños y niñas y adornado con muchas láminas, Imp. de los Herederos de la V. Pla, Barcelona, 1848.

COMEnge y Ferrer, Luis, Generación y crianza o Higiene de la familia, Barcelona, José Espasa, 1920 [19s/f]. 
Alejandro Camino, Darina Martykánová

ECHARRI, María de, Conferencia de la señorita María de Echarri, el día 24 de febrero de 1908 acerca de la Acción de la Mujer en el centro de defensa social, Tip. de la Revista de Archivos, Madrid, 1908.

ECHARRI, María de, El que siembra con lágrimas..., La novela hispano-americana, Valencia, 1927.

FROND, Victor (dir.), Le panthéon des illustrations françaises au XIXe siècle, Volumen 1, Abel Pilon, Paris, 1865.

Gallego, María Teresa, Mujer, Falange y Franquismo, Taurus, Madrid, 1983.

GIMENO DE FLAQUER, Concepción, La mujer juzgada por una mujer, Secretaría de Fomento, México, 1887 [1882].

GruZIEL, Dominika, At the Crossroads of New Catholicism and the "Woman Question»: Polish Roman Catholic Laywomens Social Activism on Behalf of Women in the Three Zones of Partitioned Poland, 1878-1918, Tesis Doctoral, Central European University, 2012.

Hildegart, La revolución sexual, Cuadernos de Cultura, Valencia, 1931.

Holl, Constantino, Mujeres ilustres. Lecturas para las jóvenes católicas, Friburgo, Herder \& Cía-Libreros-Editores Pontificios, 1923.

LAQUeUR, Thomas W., La construcción del sexo: cuerpo y género desde los griegos hasta Freud, Cátedra, Madrid, 2003.

LlonA, Miren, «Los otros cuerpos disciplinados: relaciones de género y estrategias de autocontrol del cuerpo femenino (primer tercio del siglo XX)», Arenal, 14, 1, 2007, pp. 79-108.

LlonA, Miren, «El feminismo católico en los años veinte y sus antecedentes ideológicos», Vasconia: Cuadernos de historia-geografía, 25, 1998, pp. 283-299.

LOUYER VILLERMAY, Jean-Baptiste, Traité des vapeurs ou maladies nerveuses, et particulièrement de l'hystérie et de l'hypocondrie, Volumen 1, Germer-Baillière, París, 1832.

MALEČKOVÁ, Jitka, Úrodná půda. Žena ve službách národa, ISV, Praga, 2002.

MARTYKÁNOVÁ, Darina, «El amor condenado, el amor triunfante: El género en el discurso sobre la ciencia, la religión y la nación en tres obras de Benito Pérez Galdós», Espacio, tiempo y forma. Serie V, Historia contemporánea, 29, 2017, pp. 149-179.

MARTínez, Graciano, El libro de la mujer española: hacia un feminismo cuasi dogmático, Imp. del Asilo de Huérfanos, Madrid, 1921.

Mínguez, Raúl, «¿Dios cambió de sexo? El debate internacional sobre la feminización de la religión y algunas reflexiones para la España decimonónica», Historia contemporánea, 51, 2015, pp. 397-426.

MíngueZ, Raúl, «¿Fanáticas, maternales o feministas? Monjas y congregacionistas en la España decimonónica», Hispania Sacra, 137, 2016, pp. 391-402.

MínguEZ, Raúl, «Liberalismo y catolicismo ante el espejo. La construcción de las feminidades decimonónicas», en BLASCO, Inmaculada (ed.), Mujeres, 
La soltería virtuosa: dignidad, utilidad y el discurso sobre el celibato femenino...

hombres y catolicismo en la España contemporánea. Nuevas visiones desde la historia, Tirant humanidades, Valencia, 2018.

MonsERdÁ, Dolors, Estudi Feminista. Orientacions per a la dona catalana, Lluis Gili, Barcelona, 1909.

Morales, Amalia y VieITEZ, Soledad, «Intervención femenina en el mundo rural franquista (España, 1939-1975). Las Cátedras Ambulantes de la Sección Femenina de la Falange Española y su labor de Divulgación Sanitaria y Social», Revista Questoes \& Debates, Curitiba, 65, 2017, pp. 175-205.

MiLler, Nicholas, John Millar and the Scottish Enlightenment. Family life and World History, Voltaire Foundation, Oxford, 2017.

Monlleó, Rosa, «La revolución liberal y el voto femenino: la religión como instrumento de poder», Dossiers feministes, 2, 1999, pp. 153-174.

Morcillo, Aurora, En cuerpo y alma. Ser mujer en tiempos de Franco, Siglo XXI, 2015.

MuÑoz LóPEZ, Pilar, Sangre, amor e interés. La familia en la España de la Restauración, Marcial Pons, Madrid, 2001.

Nelken, Margarita, Trampa del Arenal, Librería de los sucesores de Hernando, Madrid, 1923.

PARdo BAZÁn, Emilia, Memorias de un solterón, Tip. de Agustín Avrial, Madrid, 1896.

PÉREZ DEL PUERTO, Ángela, Más allá de las naciones. La defensa de la feminidad católica a través del proyecto educativo de acción católica en España y Estados Unidos (1940-1950), Tesis Doctoral, Universidad Autónoma de Madrid, 2015.

PÉREZ, Silvia María: «Mujeres liberadas de la tutela masculina: de solteras y viudas a fines de la Edad Media», Cuadernos Kóre, 2, 2010, pp. 46-53.

PEINADO, Matilde, Enseñando a señoritas y sirvientas. Formación femenina y clasismo en el franquismo, Catarata, Madrid, 2012.

Pro RUIZ, Juan, «Mujeres en un estado ideal: la utopía romántica del fourierismo y la historia de las emociones», Rubrica Contemporanea 7, 2015, pp. 27-46.

RAmón y CAJAL, Santiago, La mujer. Psicología del Quijote y el quijotismo, J. G. ${ }^{a}$ Perona, Madrid, 1944 [1905].

Ruíz AmADO, Ramón, ;Antes que te cases!: cartas a un joven casadero, Librería Religiosa, Barcelona, 1954 [1930].

SAlOMÓn, Pilar, "“Armémonos de valor; y por Dios y por la Patria, adelante": Definir una masculinidad para la regeneración nacional católica finisecular», en en BLASCO, Inmaculada (ed.), Mujeres, hombres y catolicismo en la España contemporánea. Nuevas visiones desde la historia, Tirant humanidades, Valencia, 2018.

SALAS, María, Nosotras, las solteras, Juan Flors, Barcelona, 1959.

SÁnCHEZ, José, «Amantes, barraganas, compañeras, concubinas clericales», Clío \& Crimen: Revista del Centro de Historia del Crimen de Durango, 5, 2008, pp. 106-137. 
Alejandro Camino, Darina Martykánová

SAZ, Ismael, España contra España. Los nacionalismos franquistas, Marcial Pons, Madrid, 2003.

ŠLEHOFER, Lukáš, «Celibát učitelek», https://perpetuum.cz/2016/09/celibat-ucitelek/, consultado a 25-10-2019.

SinuÉs, María del Pilar, Morir sola, Impr. de los hijos de J. A. García, Madrid, 1890.

VAlencina, Ambrosio, La vida espiritual o Cartas á Teófila sobre la vida interior del cristiano, Escuela Tip. Salesiana, Sevilla, 1897.

VÁzQuez, Francisco J., Mal menor. Políticas y representaciones de la prostitución (siglos XVI-XIX), Servicio de Publicaciones de la Universidad de Cádiz, Cádiz, 1998.

WaLin, Marie, «Masculinidades y diferencia de género en Higiene del matrimonio de Pedro Felipe Monlau (1853): una construcción entre los nuevos saberes científicos y la moral católica», Espacio, tiempo y forma. Serie V, Historia contemporánea, 33, 2021 (en prensa)

WeISNER-HANKS, Merry, Christianity and Sexuality in the Early Modern World: Regulating Desire, Reforming Practice, Routledge, Londres, 2000.

YEO, Eileen Janes, «The creation of 'motherhood' and Women's responses in Britain and France, 1750-1914», Women's History Review, 8, 1999, pp. 201-218.

\section{Financiación y agradecimientos}

Este artículo se enmarca en una investigación predoctoral (FPU16/02273) y en el proyecto PID2019-106210GB-I00 titulado, «Identidades en movimiento. Flujos, circulación y transformaciones culturales en el espacio atlántico (siglos XIX y XX)». Los autores agradecen a Nerea Aresti, Begoña Barrera, Irene Mendoza, Víctor Núñez-García, Javier Martínez Dos Santos, Juan Pan-Montojo y Florencia Peyrou sus comentarios y sugerencias.

\section{Datos de los autores}

Alejandro Camino es graduado en Historia y Máster Interuniversitario en Historia Contemporánea por la Universidad Autónoma de Madrid. Actualmente es doctorando en Historia Contemporánea en la misma universidad y disfruta de un contrato predoctoral FPU. Su línea de investigación principal se centra en el estudio de cómo las católicas y conservadoras españolas negocian, resisten y/o transgreden los modelos de género que se les pretende imponer. Entre sus trabajos destaca "Moldear la infancia: María de Echarri y su afán por redefinir los ideales de hombre y de mujer mediante los cuentos infantiles (1900s-1910s)» (Ayer, en 
La soltería virtuosa: dignidad, utilidad y el discurso sobre el celibato femenino...

prensa) o «Francisca Bohigas: Mujer católica, diputada y pedagoga (1928-1950)» (/bero-Americana Pragensia, 2018).

Darina Martykánová (https://orcid.org/0000-0002-5852-3096; darina.martykanova@uam.es) es historiadora y trabaja en la Universidad Autónoma de Madrid. Es coordinadora, junto con Nerea Aresti, del dosier Masculinidades, nación y civilización en la España contemporánea (Cuadernos de Historia contemporánea, 2017) y autora de varios artículos sobre el la historia de género: "La profession, la masculinité et le travail. La représentation sociale des ingénieurs en Espagne pendant la deuxième moitié du XIXe siècle» (Antoine Derouet et al., Les ingénieurs. La production d'un groupe social, Paris, 2018); "El amor condenado, el amor triunfante. El género en el discurso sobre la ciencia, la religión y la nación en tres obras de Benito Pérez Galdós» (Espacio, Tiempo y Forma, 2017). Además, investiga las profesiones científicas desde una perspectiva transnacional: Reconstructing Ottoman Engineers. Archaeology of a Profession (1789-1914), Pisa, 2010; "Luces de España: las "ciencias útiles» durante el Trienio constitucional» (con Víctor NúñezGarcía, Ayer, en prensa). 